\title{
6 HORIZONTAL INFORMATION SYSTEMS: EMERGENT TRENDS AND PERSPECTIVES
}

\author{
Kristin Braa \\ University of Oslo \\ Norway
}

Knut H. Rolland
University of Oslo

Norway

\begin{abstract}
At the brink of the new millennium, emerging trends like globalization and the Internet-as well as the buzzword "knowledge management"- have profound impacts on how business organizations design and deploy their IT solutions. Standardization and integration seem to be the common strategy-whether ERP systems, middleware-based IS, intranets, or IT infrastructures. However, in practice these systems are often heterogeneous and constrained by various socio-technical aspects. In focusing on this phenomenon, the concept of a "horizontal information system" is introduced. Drawing from examples from a maritime classification company, we take a closer look at the phenomenon and some challenges for design and deployment of such systems are discussed.
\end{abstract}

\section{Introduction}

In this paper, we investigate trends in knowledge-intensive and globally dispersed organizations in using IT for standardizing and integrating knowledge, work, infrastructure, and information systems. The term "horizontal information system" is intro- 
duced to underscore the distinct challenges facing the design, implementation and use of large-scale information systems that cut across different communities-of-practice. ${ }^{1}$ Despite enabling technologies, including the success of Internet-based technologies, the deployment of a horizontal information system is likely to be constrained by installedbase issues, social and political aspects of knowledge sharing, and the increasing sociotechnical interdependencies created. We see a tendency of moving from vertical information systems to horizontal and integrated systems that cut across the organization. Trends emerging from Internet-based technologies, such as intranets for internal organizational communication, enhance this. Other trends, such as globalization and knowledge management, support this tendency in deploying large-scale infrastructure-like information system for the entire enterprise. The general term globalization has been used to describe the increasing economic and political interdependence in the world society. These contemporary trends seem to some extent to mobilize organizations into focusing on integration of work and knowledge, and on standardization of both technology and work. These attempts at integration and standardization will involve pitfalls and challenges and the result of striving for increased control might be losing control.

A case that put into focus the challenges in designing and implementing horizontal information systems is described. The company is a maritime classification company (MCC), operating world wide as an independent foundation working with the objective of "safeguarding life, property and the environment." The MCC is a global company that comprises 300 offices in 100 countries, with a total of 5,500 employees. The horizontal information system under implementation is a classification support system designed for supporting surveyors in their inspection of ships throughout the world. We will use this case to emphasize characteristics and possible pitfalls in implementing such systems. From this rich case, we mainly emphasize aspects we find relevant for discussing challenges related to implementation of horizontal information systems. For a more detailed reading of the case, see Rolland (1999).

This paper is organized in the following way. First, we discuss trends that "drive" the deployment of horizontal information systems, the Internet, globalization, and the focus on utilizing IT for the management of knowledge. Then, the characteristics and challenges concerned with horizontal information systems are discussed in light of the above mentioned trends. Next, some of the challenges that are related to horizontal information systems are identified from a study of the deployment of a large-scale IS in MCC. Using examples from this particular case, some challenges implementing such systems are briefly outlined.

\section{Emergent Trends and Perspectives}

\subsection{The Internet Factor}

The explosive adoption of Internet technologies during the 1990s has woven local networks into a global network, making up the infrastructure of the information society. The telephone took 37 years to acquire 50 million users, the television needed 15 years to get the same amount of viewers, while the World Wide Web managed to reach 50 million

\footnotetext{
${ }^{1}$ In IT architecture terminology, horizontal/vertical systems denote ho deeply the system penetrates the architecture; e.g., a word processor is a horizontal system.
} 
surfers in about three years (Observer 1999). Nobody knows exactly how many people are connected to the Internet, but it has been estimated at between 120 million and 150 million people, and, more importantly, the number continues to grow exponentially. Our discipline is faced now with interesting challenges that must be met by both existing and new research paradigms. The Internet was initially an experimental network between contractors and computer science researchers working for the U.S. Department of Defense. From the mid-1980s and until 1990, it proved very successful as a world wide information infrastructure for faculty, staff, and students at universities and research centers. In 1991, the restrictions against commercial use of the Internet were removed. The same year, World Wide Web software was released. The Web is one of the main driving forces of the Internet, where it is being used widely by large and small businesses, by private citizens, in schools, and by consumers (Guice 1998). The Internet as a unifying concept for the development of open and simple standards has proven to be a strong force in setting the agenda for the development of commercial software. Public and private organizations recognize that they need to have an opinion about how the technology affects their business. The question is not if but how the Internet can be utilized as interaction and integration media internally in organizations and externally in interaction with customers (Braa and Sørensen 1999). The Internet as a global infrastructure plays an increasingly important role in both information systems practice and research. The ability of the Internet as a common platform to build services upon also creates expectations. Standalone information systems are expected to integrate with the global network. Internet technology supports horizontal solutions involving a variety of actors, both those behind the service and those using the service. Thus, these systems become large, heterogeneous networks that need to be aligned with an installed base of existing systems as well as practices. In this way, the Internet serves as an important integrating technology.

\subsection{Knowledge Management: Social and Political Aspects}

One of the motivations for developing large-scale IS that cut across organizational departments and functions comes from the assumption that these systems will enable knowledge sharing and thereby serve as an important tool for the establishment of an organizational memory. In management science, economics, and recently within information systems, "knowledge" has been put forward as the most valuable asset for organizations in the "knowledge-based economy" (Neef, Siesfeld, and Cefola 1998). IT has been expected to play an important role in the management of knowledge in organizations (e.g. Earl 1996; Liebowitz 1999). Several frameworks for this have been proposed in the literature. For instance, Earl (1996) defines knowledge management as consisting of knowledge systems, networks, knowledge workers, and the learning organization. Earl draws on two case studies to illustrate how IT has enabled knowledgebased strategies. However, in order to establish a knowledge-based strategy, Earl refers to challenges concerned with (1) organizational collaboration; (2) training and personal development, and (3) organizational incentives to support knowledge sharing and collaboration. These three preconditions comes close to the challenges well known from decades of research within the field of CSCW (e.g., Grudin 1994; Markus and Connolly 
1990; Orlikowski 1992b). Thus, one could argue that knowledge management comprises nothing new-it is just a rewrapping of the social and political issues involved in using IT for supporting collaboration and sharing information between different user groups. However, knowledge management as a trend can mobilize deployment of horizontal information systems in organizations. In this way, knowledge management becomes important for understanding different organizational actors' motivations and intentions and the rationale behind the design of a particular system. In our case of a major maritime classification company, one of the main objectives for developing a horizontal IS was to increase sharing and creation of knowledge in the organization. The view that knowledge can be treated as a commodity makes the state-of-the-art technologies unlimitedly enabling - downplaying the constraining factors illustrated by recent research in CSCW and IS. Even though the Internet factor and other information technologies making it technically "easier" to develop large-scale information systems, it is less evident that these systems will be successful in terms of knowledge sharing and creation.

\subsection{The Consequences of Globalization for the Design of IS}

The general term globalization has been used to describe the increasing economic and political interdependence in the world society. More specifically, Giddens (1991) describes the globalization phenomenon as time-space distanciation. In the conceptual framework of time-space distanciation, the attention is directed to the complex relation between local involvement and interaction across distance. The level of time-space distanciation is much higher now than in any other previous period, thus the relation between local and distant social forms and events becomes correspondingly stretched. This stretching process is what Giddens refers to as globalization, in the sense that the modes of connection between different social contexts or regions become networked across the earth surface as a whole. Globalization is thus defined as the intensification of worldwide social relations that link distant localities in such a way that local happenings are shaped by events occurring many miles away and vice versa. Globalization is to be understood as a dialectical phenomenon, in which events at one pole of a distanciated relation often produce divergent or even contrary occurrences at another. For Giddens, modernization and globalization are closely connected. Globalization is the most visible form modernization is taking today and risk society is emerging (Beck 1992). Everything is connected to everything, the interdependency increases and control decreases. Increasing risk means decreasing control. Traditionally, modernization implied increased control in line with Beninger's (1986) outline of the "control revolution." More knowledge and more and better technology implied increased control. In the age of high modernity and globalization, more knowledge may just as well lead to more unpredictability, more uncertainty, and less controllability (Hanseth and Braa 2000). This shift, which may appear contradictory, can be explained by the increasing role of sideeffects (Beck, Giddens, and Lash 1994). Globalization means integration. At the same time, all change-new technologies introduced, organizational structures and work procedures implemented, etc.- has unintended side-effects. Any change may affect those interacting with processes being involved in the change. Side-effects of local events often have global consequences. And the more integrated the world becomes, the longer and 
faster side-effects travel and the more significant their consequences will be. Globalization also means globalization of side effects.

In the so-called information economy it has been argued that IT and globalization are reinforced by each other (Bradley, Hausman, and Nolan 1993; Castells 1996), and that these processes will shape markets and the way businesses compete. Interestingly, this will also change the way organizations use IT-how information systems are designed - and the motivations for developing these systems. In this context, the IS-related literature seems to recommend that global organizations utilize IT for increasing control and coordination (e.g., Ives and Jarvenpaa 1991). Earl and Fenny (1996) suggest that global and large-scale information systems have the potential to contribute to the global efficiency, local responsiveness, transfer of learning, and making global alliances. The role of IT as a key factor to bring these changes about is often thought of as an opportunity to increase control and enhance coordination, while opening access to new global markets and businesses (Ives and Jarvenpaa 1991). Bartlett and Ghoshal (1998) claim that firms operating in this global markets will increasingly be at a serious strategic disadvantage if they are unable to firmly control their worldwide operations and manage them in a globally coordinated manner. Within this model, corporations are focusing on more close coordination of increasingly more complex and global processes. At the same time, globalization is experienced as creating an increasingly more rapidly changing, dynamic, and unpredictable world.

In a variety of businesses and organizations, there seems to be a growing trend to build large-scale horizontal information systems. More specifically, these can be categories of systems such as enterprise resource planning (ERP) systems, in-house developed client/server systems based on middleware architectures, or large intranets based on Internet technologies and standards. Typically, these are systems that cut horizontally across the organization aiming at integrating and standardizing the organization's business processes. IS research on these topics, focusing on the socialtechnical processes that take place when organizations are deploying large-scale information systems, are few. Davenport (1998), who has surveyed the recent trends in enterprise systems, notes that information integration and standardization may reduce flexibility by imposing their own logic on the company's strategy, culture, and organization. On the other hand, some organizations may well succeed in implementing such systems. Similarly, in the contemporary discussions around information infrastructures, it has been shown how design and redesign of such large-scale systems are constrained by an installed base of systems, standards and practices (Star and Ruhleder 1996).

Thus, globalization and growing unpredictability, uncertainty, and less control cause profound consequences for how organizations use IT and deploy large-scale information systems. IT and information systems are not unlimitedly enabling technologies that corporations can deploy to increase strategic advantages in terms of information integration and a standardized IT infrastructure. These technologies are inevitably connected to larger social systems, which in turn impose a variety of socio-technical constraints on the use of IT. For instance, IT plays a key role in the implementation of "flexible specialization" models by enabling more flexible production systems. On the other hand, as seen in the case of implementing SAP in a global organization (Hanseth and Braa 1998), large and complex IT infrastructures may block the changes in 
organizational structures and processes necessary for a global company to excel in the global market. Thus, in this perspective, technology becomes an actor, which may decrease the number of possible redesigns and hence, in this way, technology in general becomes both enabling and constraining (Orlikowski 1992a). This insight suggests IT will be both constraining and enabling for global organizations in increasing their control and coordination. In addition, since information technologies and systems become an integral part of almost any work process, this ultimately increases the interdependencies between different work processes and between those practices and the technologies involved.

\section{Horizontal Information Systems}

In the 1970s, Galbraith (1973) claimed that the uncertainty faced by organizations was due to insufficient information. Uncertainty was defined as the difference between the information needed for the successful execution of an organizational task and the information available in the organization. Consequently, the information processing abilities of the organization had to be increased as the organization faced increasing uncertainty. In Galbraith's information processing model of the organization, one design strategy could be to deploy vertical information systems in order to increase the information processing abilities and avoid an overheated hierarchy. As illustrated in our case of a maritime classification company, information technologies and standards for interoperability and computer networking, combined with visions of (global) knowledge sharing and information integration-represent a shift toward deploying horizontal information systems. This shift from vertical and local information systems-to horizontal and global information systems comes with a range of new business opportunities as well as distinct challenges and pitfalls.

Horizontal information systems are different from traditional information systems in how they handle typical support for different communities in the organization or between organizations. Typically, traditional information systems focus on feeding the upper levels (i.e., strategic management) of the organization with relevant information for making decisions. Moreover, in this world, it was relatively easy to point to the typical users, making it possible to design the system for a special group of users (i.e., managers and secretaries). In short, the focus was on automating vertical information processing through a transaction processing system. A typical example is a payroll system used by the administrative staff for information on employees, salaries, and the production of payslips. In addition, management might use the system for planning staff levels and promotions, or for reporting to the tax office.

\subsection{Characteristics and Challenges}

In describing and understanding large-scale information systems as a phenomenon, we draw from insights given by theories of globalization (Beck 1992; Giddens 1991). The term horizontal information system is used to denote the distinct characteristics and challenges concerned with deploying large-scale information systems. However, horizontal information systems are neither a clear-cut concept nor a solution for how to 
deploy large-scale information system, but rather a perspective in order to offer a way of understanding this contemporary phenomenon. Horizontal IS imply that work practices as well as different technologies become increasingly interconnected and integrated, and accordingly, these systems become more vulnerable to unintended side-effects. Therefore, systems that are deployed for increased control can ultimately turn out to imply less control, because of the side-effects introduced. Since horizontal IS typically cut across functions, stakeholders, and communities of practice within an organization, the deployment of such systems faces some distinct challenges:

- Increasing the interdependencies in the organization. The deployment of a horizontal IS in an organization implies that different communities of practice will be connected more closely. This implies increasing the number of interdependencies between technologies and work practices in the organization. The growing sociotechnical interdependencies make it almost impossible to distinguish between the technical and the non-technical issues, which in turn constrains the use of IT and the deployment of a horizontal IS in the organization. Linking different communities of practice also has social and political aspects, as for instance how employees share their knowledge through a horizontal IS depends on non-technical structures in the organization (e.g., reward systems, professions).

- Undermining the interpretative flexibility of artifacts. In real-time and real-life work practices, artifacts can have multiple meanings according to context and the situation. Artifacts are a profound part of work practices, and following Law (1992), the social is made up of heterogeneous networks of both materials and humans. Thus, artifacts and work practices are intrinsically linked in heterogeneous networks that constitute the focal social system, which coordinates and ensures a smooth flow of work. As a horizontal IS is used in different local contexts where artifacts are embedded in different practices, discovering the different roles and meanings of the artifacts becomes increasingly important for not undermining the "workflow from within" (Bowers, Button, and Sharrock 1995) or establishing a new workflow from within through a horizontal IS.

- $\quad$ Lack of control because of unintended side effects created. Unintended side-effects can be caused by both human conduct and non-humans, as for instance software and hardware. In the case of large software systems, for example, it is conventional wisdom that maintenance and correction of errors, in fact, often introduces new errors. When interdependencies are established through a horizontal IS, side-effects will not be isolated but distributed. Thus, the processes involved when deploying horizontal IS would be less controllable and involve negotiations for aligning the actors' interests.

- Necessity of continuouslynegotiating and maintaining interfaces. Horizontal IS will typically provide interfaces to other systems. For instance, a large-scale intranet may have interfaces to old legacy systems and databases. Horizontal IS are often deployed to replace the organization's fragmented way of storing information and the current information systems. At the same time and to a certain degree, the horizontal IS must extend the old information infrastructure. 
- Aligning the variety of different communities of practices. A horizontal IS will, in most cases, not be perfectly aligned with different practices in different communities. However, this does not imply that the system is a failure or that improvisations and work-arounds are done by the users in order to compensate for "bad" design. Improvisations and work-arounds are part of human conduct for securing a smooth flow of work. On the other hand, the design must not undermine the users' possibility for improvising and adjusting the system to their work situation. Thus, the challenge is to balance between standardization and flexibility - not to describe a "correct" set of requirements for supporting special work practices.

- Horizontal IS constitute an installed base. When horizontal IS become stabilized and institutionalized in the organization, they tend to have infrastructural characteristics - e.g., they become increasingly hard to change and, at the same time, the pressure for doing necessary changes increases (Monteiro 1998). In this way, a horizontal IS in an organization will constitute a powerful installed base.

These are all challenges that have to be considered to some extent when implementing a horizontal information system. There will, of course, be variations according to, for instance, how deeply the horizontal IS penetrates the work practice. An intranet service providing biographical data of the employees will not have the same implication as implementing a patient record system at a hospital.

\subsection{Related Research}

\subsubsection{Information Infrastructure}

The term information infrastructure has been used to describe large-scale networked structures that often cut across work-practices, departments, functions, and organizational borders (e.g., Bud-Frierman 1994; Monteiro and Hanseth 1995; Rolland 1999; Star and Ruhleder 1996). Hence, any horizontal information system could also be defined as an information infrastructure, but not necessarily the other way around, as a horizontal information system will focus more on supporting more or less specific activities for different communities-of-practice. Information infrastructures, however, as the term is used in the literature, span from tailor-made large-scale collaborative systems (Star and Ruhleder 1996), large EDI networks (Monteiro and Hanseth 1995), national information infrastructures (Branscomb and Kahin 1995), to the Internet (Monteiro 1998). BudFrierman states that the concept of an information infrastructure is a potentially useful unit of discourse, being both a historical and cultural entity in addition to being used to describe both micro- and macro-level structures.

In general, an information infrastructure can be understood as a term for describing the heterogeneous, dispersed, complex, and interdependent components, which our "work" relies on to collaborate and coordinate activities through sharing and interchange of information in a given context. Along these lines, an information infrastructure becomes a socio-technical phenomenon. Information infrastructures are always more than cables, communication protocols, routers, and computers. More specifically, 
Hanseth (2000) emphasizes that an information infrastructure is evidently an enabling, shared, open, socio-technical, and heterogeneous installed base. An information infrastructure is never built from scratch, and there will always be an installed base in terms of a heterogeneous social system consisting of technical as well as non-technical components. An infrastructure is a set of connected and interconnected components, which can be conceived as "ecologies of infrastructures" (Hanseth 2000). One infrastructure consist of ecologies of sub-infrastructures by:

- building one infrastructure as a layer on top of another;

- linking logical related networks; and

- integrating independent components, making them interdependent.

In this way, a horizontal information system could be understood as a component in a larger information infrastructure. Similarly, according to Star and Ruhleder (1996), an information infrastructure cannot be understood as pure technology, but an Information Infrastructure is always embedded in a larger social structure. Moreover, Star and Ruhleder emphasize that an infrastructure is something that develops in relation to practice, it is not to be conceived as a "thing" or a static technical structure, and the question becomes "When is an infrastructure?" not "What is an infrastructure?" Consequently, "an infrastructure occurs when the tension between local and global is resolved" (Star and Ruhleder 1996, p. 114). Thus, this information infrastructure discussion focuses on some interesting aspects that increasingly are met when designing and deploying large-scale information systems. For instance, the focus on the installed base, that is, the understanding that you can never develop a system from scratch, there is always something there in the form of social practices, artifacts, and very often a heterogeneous collection of different information systems.

In using the term horizontal information systems, we are interested in discovering the socio-technical processes surrounding the alignment between different practices, artifacts, the old information systems, and new systems and technologies. For instance, why is an information system successfully aligned within one context, whereas it can be totally misaligned in a different context? How do we design and implement information systems that cut across different contexts? Furthermore, how is this integration process shaped by the existing artifacts (i.e., paper documents) and work practices, and in what ways are an installed base enabling and constraining for a certain information system to be implemented?

\subsubsection{Communities of Practice and Artifacts}

One aspect of designing large-scale information systems is that they cut across several communities-of-practice. The term communities-of-practice has been used to denote a social group where a certain practice is common, coordinated, and reproduced (Brown and Duguid 1991). Thus, in any large organization, there will typically exist numerous communities: an organization can be described as a community-of-communities. Artifacts, whether information systems or paper documents, play important roles in a community-of-practice were they mediate relations and coordinate activities, both within 
the community and between different communities. Usually, artifacts are not universally interpreted among different communities-of-practice. When deploying horizontal information systems, information provided by the system can be interpreted very differently within different communities-of-practice. Furthermore, when information, which earlier existed on paper documents, as for instance standardized reports or checklists, becomes part of a horizontal information system, the information provided can be interpreted differently. Artifacts like paper documents have been recognized for having material and social aspects that are important for the meaning of the information inscribed on them (Braa and Sandahl 1998; Brown and Duguid 1994). For instance, Braa and Sandahl describe an attempt at a news agency, to implement paper-based TV schedules into a document information system. The design of the new document information system failed, because one of the resources that the users relied on in their work practice was not considered relevant for the design. At the news agency, faxes and shelves indicated progress and states of the work process and, since this work process was visible to all workers at the office, the artifacts played an important role in coordination of the work. In the document information system, this coordination mechanism did not exist and subsequently the system broke down.

\section{From Local and Vertical to Global and Horizontal}

\subsection{The Case of MCC}

During the 1990s, Maritime Classification Company (MCC) has been challenged through increased global competition and swift changes that have effected their business environment. An important part of MCC's strategy to meet these challenges has been to deploy IT with the intention of reengineering their way of working and become a "learning organization." This alignment of the business strategy and the IT strategy indicated a shift from a local and vertical IS toward a more global and horizontal information system. In 1997, as a part of this strategy, MCC invested approximately US\$ 52 million in common infrastructure and a large-scale information system. In this paper, the large-scale information system implemented will be referred to as the horizontal information system. The common IT infrastructure was launched in 1997-98 under the mantra "one world - one MCC" and comprised a WAN that links 300 offices, common NT servers, office applications, common e-mail system, and shared document databases.

In addition to the global infrastructure campaign, MCC had, since 1993, been working on the horizontal information system for supporting the work of the surveyors as well as the information requirements of managers and customers. The vision was that the horizontal information system would enable knowledge sharing and transparent access to all relevant information on vessels, certificates, surveys, etc., regardless of roles, departments, and positions in the organization. The prominent idea was to integrate all relevant information for classification of vessels in a common product model. A product model is a standardized representation of all parts of a ship and the relationships between those parts. This common product model was developed using the UML modeling language and additional CASE tools and serves as the common standard for the 
horizontal information system. In short, the horizontal information system is a state-ofthe-art client/server system built on Microsoft's COM architecture as middleware and a common SQL-based relational database as a server. The system was planned to be implemented in December 1997; however, due to the complexity of the technological solution and changing requirements, it was not put in use until early in 1999.

\subsection{Local Variations and Standardization}

\subsubsection{The Horizontal Information System}

MCC has systematically worked for streamlining and standardizing their work processes and several projects have been undertaken to define new work processes. As an overall strategy, MCC has emphasized standardization on three different levels: (1) common work processes; (2) common product model serving as a standard for the horizontal information system; and (3) common IT infrastructure (Figure 1).

Sharing knowledge through the horizontal information system implied, to a certain extent, that the terminology and the representation of knowledge used were agreed upon. To solve this problem, MCC developed a large product model as a standardized information model for all applications comprising the horizontal information system. The idea was to represent product data, as well as work tasks, on a standardized form to make it possible to share knowledge through the system between the different offices. However, system developers and others soon realized that the challenges with developing

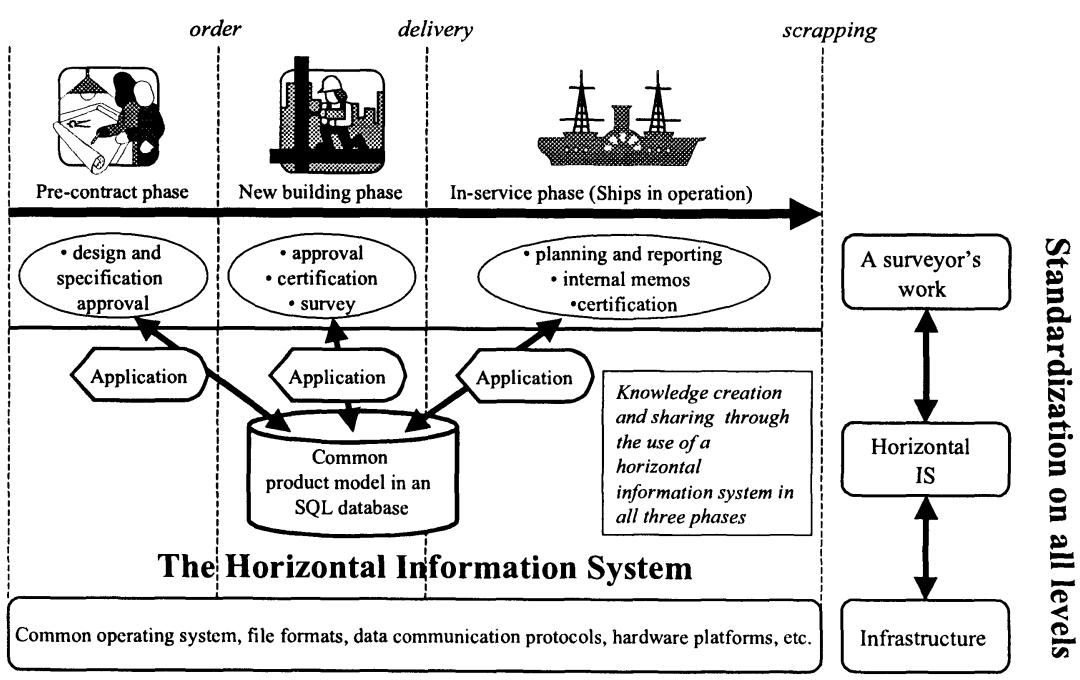

Figure 1. Life-Cycle Information Management in MCC 
such models were not only of a technical character, but organizational and political as well. A manager from the software development project pointed at the fact that, historically, different departments and groups in the organization had used different terminology and that a "stiffener" was not a "stiffener" throughout the organization.

The knowledge-intensive nature of the surveyors' work made it considerably challenging to predefine and standardize this work and to design IT systems that would not pose too many constrains for their situated and context dependent work. The surveyors play an important role in the organization by conducting various types of surveys on vessels. Their work involves both practical work (e.g., investigating machinery and technical equipment on a vessel) and office work (e.g., writing technical reports, communicating with customers, using computer applications, etc.). In this way, the surveyors' work can be characterized as knowledge-intensive. Surveyors have to keep up with changing rules and regulations concerning certification as well as technical knowledge within a variety of disciplines (e.g., materials engineering, propulsion systems, hydrodynamics, electronics). MCC is authorized for doing surveys and certification on behalf of more than 130 national administrations. In addition, surveyors do surveys based on MCC's own classification rules and IMO (International Maritime Organization) regulations. In doing their daily work, the surveyors draw upon experience-based and tacit knowledge. For instance, the surveyors draw from their tacit knowledge to intuitively find those spots on a vessel's hull that could have cracks or rust. Similarly, they do considerable work before the survey to gain as much explicit knowledge of the vessel as possible. For instance, they have to know the status of the ship, in terms of length, tonnage, flag, and information on the owner of the ship. Thus, the surveyors' tacit and explicit knowledge as well as their communication skills are all factors that determine MCC's accumulated capability for safeguarding life and property.

According to the surveyors interviewed, the implementation of the new horizontal information system led to considerable changes in the role of the surveyor. Some meant that this new system would make the surveyors more or less "data collectors" for MCC. They would spend considerably less of their time "out in the field" doing practical engineering work as more of their time would be occupied doing office work.

\subsubsection{Communities-of-practice within MCC}

As a global organization, MCC consists of several different communities-of-practice. The differences between these communities were recognized during the design, implementation, and use of the new horizontal information system. In particular, the different interpretations and interests were visible when designing and implementing the horizontal information system with the intention of sharing knowledge throughout the global organization and standardizing the work done in different communities. This posed special challenges and problems for the design as well as the implementation of the system.

The surveyors are not one homogenous group, but more or less autonomous engineers that work in different offices around the world. Surveyors in the MCC organization are working with different kinds of surveys according to where the ship is in its life cycle (Figure 1). Even before a ship is designed and constructed, the ship owner 
decides to classify the new ship according to the MCC classification rules. An MCC surveyor must certify all components that are to be installed on the ship and their manufacture. In this process, the MCC surveyor and the yard that is building the ship would benefit from information on previous ship designs and components. It would be extremely helpful for a surveyor to know if other surveyors have recognized any typical failures or safety hazards concerning a specific design or component. Other surveyors specialize in doing surveys on ships that are in operation. Different communities of surveyors have different views on, for, instance how different components of a ship are related. These issues made it extremely difficult for the system developers to describe the "correct" requirements for the horizontal information system.

MCC is a global organization where the different local stations are embedded in cultural and institutional environments that have different degrees of similarity. For instance, at one MCC office in Germany, the engineers insisted on writing additional comments in German instead of using "standard texts" in English. At this office, all of their customers have similar requirements and their primary focus is on delivering results in the form of technical reports as efficiently as possible. At this office, the requirement was to have an integrated IS where they avoided entering the customer's address and name more than once. In a small Norwegian office, however, the surveyors' work is more varied and this functionality is not required. On the contrary, they focus on flexibility in the IT support and that the different IT applications they use should have a consistent user interface.

Cultural differences in the division of labor make it difficult to design a system that standardizes work processes. In Eastern countries, the surveyor role was different. For instance, in Asia it was culturally determined that doing office-like work was the job of a secretary. Consequently, the users of the horizontal information system in Eastern countries would most likely be secretaries and not surveyors.

Regarding the design of a horizontal IS, these examples illustrate the challenges involved when developing a system to be used by different communities of practice. As noted in section 3, this underscores that a horizontal IS will, in most cases, not be perfectly aligned with different practices in different communities. But, on the other hand, such systems could be successful if they link different communities of practice without undermining the communities' internal practices.

\subsection{Standardization and Flexibility}

\subsubsection{Negotiating and Maintaining Interfaces}

The surveyors have established a system of different paper-based checklists for supporting the different types of surveys conducted by a surveyor in MCC. There are a total of 74 different checklists to be used with different kinds of surveys and types of vessels. The checklists were constructed by different people for different contexts and environments. Thus, there is no standard representation or common use of terminology, and these checklists have not been a part of the official documentation given to the customers. On the other hand, these checklists have been most helpful for inexperienced surveyors who use them down to every detail, and in this way they are learning what to 
focus on when conducting a survey of a vessel. More experienced surveyors usually do not follow the items in the checklists when conducting a survey-they only use it in a very limited way.

The initial plan for the horizontal information system was to include a standardized version of these paper-based checklists, in order to structure the input of information. This standardized way of reporting the survey information was required, because this information was used in the generation of various survey reports. This created several dilemmas for the implementation and use of the new information system. The strategy was to include a very standardized set of checklists in order to be able to generate statistical information from the surveyors reporting through the standardized checklists. In the later stages of development and during implementation, this strategy was abandoned due to the organizational and technical complexity. Different groups of surveyors and system developers had to agree upon a common terminology and a general breakdown structure of a ship, which turned out to be a longitudinal and complex process. In addition, the systems developers had already programmed a version according to the product model philosophy that for various reasons did not meet some of the surveyors' requirements. This meant that the complex product model had to be changed, which in turn required an effort of modeling and programming.

This exemplifies the necessity of negotiating with different interest groups in order to obtain the needed flexibility in the design. The interdependencies created through a horizontal IS, and the interconnectivity between technical and non-technical issues, imply that many seemingly technical design decisions become an issue for negotiation. This makes such systems difficult to plan and increasingly difficult to change as the development proceeds.

\subsubsection{Aligning the Variety of Communities of Practice}

One of the main reasons for standardizing the checklists was to create a standardized set of data to support the automatic production of reports. Some of these reports are used in communication with officers and crew on a ship. For instance, when the surveyor has conducted a survey on a vessel, a preliminary survey report and a memo to the owner of the ship are given to a member of the crew on the ship. These reports summarize the job that has been done and what the surveyor found during this particular survey. The surveyor fills in the reports onboard the ship and then their meaning is carefully explained to the ship officers or other members of the crew. It is of profound importance that any "Conditions of Class" are fully understood, so that the crew is able to do the required repairs and adjustments in order to maintain the safety for crew and cargo on the ship. In this context, the reports are artifacts that act as mediators in the communication between the surveyor and different members of the crew. Some of the surveyors stated that the information on the reports generated by the horizontal information system did not have a meaningful structure for the surveyors using the system. For instance, one of the reports was structured according to the alphabetical order of the codes related to the different surveys. The surveyors, on the other hand, were used to categorize the information according to different components of the ship (e.g., hull, machinery, propellers, thrusters). Changing the structure on the reports also has implications for how the surveyors 
communicate with the crew on a ship. According to the surveyors, some crew members found it easier to understand concrete things like hull and propellers compared to MCC's abstract four letter codes. The surveyors had different ways of compensating for avoiding this situation. For instance, the surveyors took their time in explaining every detail in the reports for the crew. In addition, attempts were made to change the standardized templates for the reports included in the horizontal information system. Since these templates were plain Microsoft Word files, it was possible for the surveyors to locally modify the templates and, in this way, restructure the contents of the automatically generated reports. However, since it was not possible to save a new version of a template into the system, this work-around created some problems, and the users were strictly prohibited from modifying the templates. By modifying the templates for the reports, there would exist two (or more) versions of the same report: one for the user that had modified the local template and one for all others who accessing that particular report through the horizontal information system. Thus, this created a serious dilemma: the reports should be tailored to different customers' needs, but at the same time, only one version of the same report. should exist

This underscores why it becomes increasingly important to allow flexibility in use in supporting knowledge-intensive work in different communities-of-practice with a horizontal IS. Prior to the implementation of the system, the survey reports were often tailored according to whom the surveyor was going to meet on the ship. In addition, numerous types of surveys were conducted during the visit on the ship, leading to complex survey reports supposed to support the communication between the surveyors and the crew. Thus, how these reports are structured is extremely context dependent, and the need for flexibility for the surveyors to modify the generated reports becomes a prerequisite for useful reports. But, with the implementation of the horizontal information system, this flexibility vanished, leading to several work-arounds and potentially different versions of the same report.

\subsection{Installed Base Issues: Unintended Side Effects}

The design and implementation of the horizontal information system was considerably constrained by an installed base. The mainframe system that had to be used in parallel with the new system especially affected not only the design and implementation processes, but also how the surveyors used the system. In this way, the mainframe system became an actor, which had to be considered in all phases of development and use. However, interestingly, this mainframe system was at first regarded as a resource and not as a constraint.

Clearly, for both technical and organizational reasons, it was impossible to implement the system in all 300 offices simultaneously. Hence, for a period, the old mainframe system had to be used in parallel with the horizontal information system. Offices using the old Mainframe System and those using the Horizontal Information System are dependent upon having correct and updated information when planning and reporting surveys. In order to update the common database used by the horizontal information system with data from the mainframe system and vice versa, various scripts were made. In other words, the installed base made it necessary to develop a gateway, 
because a discrete transition from the old system to the new system was impossible. Due to the complexity of the product model, the technically different databases used, as well as several adjustments in the design, it was difficult to ensure perfect updates between the mainframe system and the horizontal information system. Thus, the mainframe system represented an important part of the installed base that had to be considered in the design and implementation processes. However, the installed base issues were not considered until the new horizontal information system was tested with what was considered as relevant data. The data in the mainframe system, which had at first been considered as an enabling resource to be included in the new horizontal information system, became a constraint for the design and implementation. Furthermore, this had unintended sideeffects that increased the surveyors' distrust of the new horizontal information system. In using the new system, some of the surveyors experienced losing some of their information because of the imperfect gateway between the two systems' databases. The surveyors had to enter the information into the system several times, and hence, this made their office work more time consuming and stressful. This increased the distrust of the horizontal information system, and thereby created work-arounds. Some of the surveyors stated that they were more careful not to enter too much data into the system at a time. At the same time, one of the intentions with the horizontal information system was to support more detailed, consistent, and a larger amount of information than before. In fact, the unintended side effects of the horizontal information system may have led to the opposite; namely, that the surveyors report less information than before. This distrust toward the new system caused the surveyors to double check the information provided. For instance, they constantly used a large book containing information on all vessels classified by MCC and compared the information in this book with the information on the screen.

\section{Challenges in Implementing Horizontal Information Systems}

The possibility of gaining benefits of integration suffers from the complexity created by increasing the interfaces that need to be negotiated and maintained. Thus, side effects may be difficult to control. Developing and deploying the horizontal information system at MCC illustrate how seemingly technical issues are inherently interconnected with nontechnical issues such as work practice of the different communities; the various cultural and institutional environments; distrust toward the system, and so forth. The involvement of different communities-of-practice, an installed base, and the somehow fluctuating requirements for the system made the implementation process a dynamical and complex process of negotiating and adjusting current designs. According, implementation of an information system that cuts horizontally across practices, departments, and cultures is considerably more time consuming than in the case of the more traditional systems. Drawing from actor-network theory (e.g., Callon 1991; Latour 1991; Law 1992), it can be argued that, in the deployment of such horizontal information systems, one is actually trying to change considerably larger networks, compared to traditional information systems. Thus, it is difficult to implement a horizontal IS all in at once. The old system, which had to be used in parallel, not only affected the design and implementation process, but also how the surveyors used the system. Further, the horizontal IS itself becomes an 
installed base that could constrain redesigns as well as further development of new systems. Huge resources are invested and interdependencies created and thus it becomes impossible to reverse the process.

The challenges concerning the design of large-scale information systems are neither local nor global, they are, rather, horizontal, and thus the question is not how to achieve a seamless integration between existing local practices-or a global and all embracing standard. Using IT in a flexible way that enables knowledge sharing in communities-ofpractice, as well as linking the various communities in ways that do not undermine local work practices, is challenging. Emerging trends such as Internet technologies, globalization, and knowledge management are influencing the way information systems are designed. In describing and understanding horizontal information systems as a phenomenon, we draw from insights given by theories of globalization (Beck 1992; Giddens 1991). The concept of horizontal information systems is introduced in order to emphasize challenges to be met in implementing large scale information systems that cut across communities-of-practice. Such systems do not exist in isolation, but interact with various other systems, artifacts, and practices; relations are continuously negotiated and almost never reach a stable state as a typical "infrastructure." As shown in this case, there is a need for flexibility and the variety of communities-of-practice will "fight" the standardization attempt by means of their local practice. However, a certain degree of standardization is needed in order to communicate across practices and borders.

\section{References}

Bartlett, C. A., and Ghoshal, S. Managing Across Borders: The Transnational Solution. Boston: Harvard Business School Press, 1989.

Beck, U. Risk Society: Towards a New Modernity. London: Sage, 1992 (first published in German as Risikogesellscahft, 1988).

Beck, U., Giddens, A., and Lash, S. Reflexive Modernizations-Politics, Tradition and Aesthetics in the Modern Social Order. Cambridge, UK: Polity Press, 1994.

Beniger, J. R. The Control Revolution. Technological and Economic Origins of the Information Society. Cambridge, MA: Harvard University Press, 1986.

Bowers, J., Button, G., and Sharrock, W. "Workflow from Within and Without: Technology and Cooperative Work on the Print Industry Shopfloor," in Proceedings of the Fourth European Conference on Computer-Supported Cooperative Work, ECSCW'95, H. Marmolin, Y. Sundblad, and K. Schmidt (eds.), Stockholm, 1995, pp. 51-66.

Braa, K., and Sandahl, T. I. "From Paperwork to Network: A Field Study," in Proceedings from the Third International Conference on the Design of Cooperative Systems, Cannes, France, May 26-29 1998.

Braa, K., and Sørensen, C. “The Internet Factor,” Scandinavian Journal of Information Systems (10:12), 1986.

Bradley, S. P, Hausman, J. A., and Nolan, R. L. (eds.). Globalization, Technology, and Competition. Boston: Harvard Business School Press, 1993.

Branscomb, L. M., and Kahin, B. "Standards Processes and Objectives for the National Information Infrastructure," in Standards Policy for Information Infrastructure, B. Kahin and J. Abbate (eds.). Cambridge, MA: MIT Press, 1995.

Brown, J. S., and Duguid, P. "Organizational Learning and Communities-of-practice: Toward a Unified View of Working, Learning, and Innovation," Organization Science (2:1), 1991, pp. 40-57. 
Brown, J. S., and Duguid, P. "Borderline Issues: Social and Material Aspects of Design," HumanComputer Interaction (9), 1994, pp. 3-36.

Bud-Frierman, L. (ed.). Information Acumen - The Understanding of Knowledge in Modern Business. London: Routledge, 1994.

Callon, M. "Techno-economic Networks and Irreversibility," in A Sociology of Monsters - Essays on Power, Technology and Domination, J. Law (ed.). London: Routledge, 1991.

Castells, M. The Rise of the Network Society. Oxford: Blackwell Publishers, 1996.

Davenport, T. H. "Putting the Enterprise into the Enterprise System," Harvard Business Review, July-August 1998.

Earl, M. J. "Knowledge Strategies: Propositions From Two Contrasting Industries," in Information Management-The Organizational Dimension, M. J. Earl (ed.). Oxford: Oxford University Press, 1996.

Earl, M. J., and Fenny, D. F. "Information Systems in Global Business: Evidence from European Multinationals," in Information Management-The Organizational Dimension, M. J. Earl (ed.). Oxford: Oxford University Press, 1996.

Galbraith, J. Organization Design, Reading, MA: Addison-Wesley, 1973.

Giddens, A. Consequences of Modernity. WHERE: Polity Press, 1991.

Grudin, J. "Groupware and Social Dynamics: Eight Challenges for Developers," Communications of the ACM (37:1), 1994, pp. 92-105.

Guice, J. "Looking Backward and Forward at the Internet," The Information Society (14:3), 1998.

Hanseth, O. "Infrastructures and the Economy of Standards," in From Control to Drift: The Dynamics of Corporate Information Infrastructures, C. U. Ciborra, K. Braa, A. Cordella, B. Dahlbom, A. Failla, O. Hanseth, V. Hepsø, J. Ljungberg, E. Monteiro, and K. A. Simon (eds.). Oxford: Oxford University Press, 2000.

Hanseth, O., and Braa, K. "Technology as a Traitor: Emergent SAP Infrastructure in a Global Organization," in Proceedings of the Nineteenth International Conference on Information Systems, R. Hirschheim M. Newman, and J. I. DeGross (eds.), Helsinki, December, 1998, pp. 188-197.

Hanseth, O., and Braa, K. "Globalization and 'Risk Society'," in From Control to Drift: The Dynamics of Corporate Information Infrastructures, C. U. Ciborra, K. Braa, A. Cordella, B. Dahlbom, A. Failla, O. Hanseth, V. Hepsø, J. Ljungberg, E. Monteiro, and K. A. Simon (eds.). Oxford: Oxford University Press, 2000.

Ives, B., and Jarvenpaa, S. L. "Applications of Global Information Technology: Key Issues for Management," MIS Quarterly, March 1991, pp. 32-49.

Latour, B. "Technology is Society Made Durable," in A Sociology of Monsters-Essays on Power, Technology and Domination, J. Law (ed.). London: Routledge, 1991.

Law, J. "Notes on the Theory of the Actor-Network: Ordering, Strategy, and Heterogeneity," Systems Practice (5:4), 1992, pp. 379-393.

Liebowitz, J. (ed.). Knowledge Management Handbook. Washington, DC: CRC Press, 1999.

Markus, M. L., and Connolly T. "Why CSCW Applications Fail: Problems in the Adoption of Interdependent Work Tools," Proceedings of the Conference on Computer-Supported Cooperative Work. New York: ACM, 1990, pp. 371-380.

Monteiro, E. "Scaling Information Infrastructure: The Case of Next-Generation IP in the Internet," The Information Society (14:3), 1998, pp. 229-245.

Monteiro, E., and Hanseth, O. "Social Shaping of Information Infrastructure: On Being Specific About the Technology," in Information Technology and Changes in Organizational Work, W. Orlikowski, G. Walsham, M. R. Jones, and J. I. DeGross (eds.). London: Chapman \& Hall, 1995.

Neef, D., Siesfeld, G. A., and Cefola, J. (eds.). The Economic Impact of Knowledge. London: Butterworth-Heinemann, 1998.

Observer. "Guide to the Internet," The Observer, January 17, 1999, pp. 32. 
Orlikowski, W. J. "The Duality of Technology: Rethinking the Concept of Technology in Organizations," Organization Science (3:3), 1992a, pp. 398-427.

Orlikowski, W. J. "Learning from Notes: Organizational Issues in Groupware Implementation," in Proceedings of the Conference on Computer-Supported Cooperative Work. New York: ACM, 1992b, pp. 362-369.

Rolland, K. "Information Infrastructure Transition: Challenges with Implementing Standardised Checklists," in Proceedings of the Twenty-second Information Systems Research Seminar in Scandinavia, T. K. Käkölä (ed.), Keuruu, Finland, 1999, pp. 95-110.

Star, S. L., and Ruhleder, K. "Steps Toward an Ecology of Infrastructure: Design and Access for Large Information Spaces," Information Systems Research (7:1), 1996, pp. 111-134.

\section{About the Authors}

Kristin Braa is an associate professor at the Department of Informatics at the University of Oslo, Norway. She has for several years done research within participatory design, digital documents, interdiciplinarity in research, integration, and geographically dispersed information systems. She has edited the books Net Society (in Norwegian) and Planet Internet (with Bo Dahlbom and Carsten Sørensen). Kristin can be reached by e-mail at kbraa@ifi.uio.no.

Knut H. Rolland graduated with a degree in informatics from the Norwegian University of Technology and Science in 1997. He has since 1998 been a Ph.D. student in informatics at the University of Oslo. His main interests include the interplay between IT and organization, particularly the design and implementation of large-scale information systems and infrastructures. Knut can be reached by e-mail at knutr@ifi.uio.no. 